\title{
Improving dimensional stability of Populus cathayana wood by suberin monomers with heat treatment
}

\author{
Runhua Zhang, \\ Erni Ma
}

\section{Introduction}

As a biocomposite, the unique characteristics of wood, such as esthetic grain, great workability, high ratio of strength-toweight, thermal insulation as well as environment-conditioning ability, make it a natural material for decoration, furniture, and construction. However, wood is a natural hygroscopic material. The main chemical components of wood are cellulose, hemicelluloses, and lignin, which have a large number of hydroxyl groups leading to dimensional instability, especially from polysaccharides (Huang et al. 2018). The dimensional changes of wood are different in the main anatomical directions due to its anisotropy. Therefore, warping, cracking, and

$\square$ MOE Key Laboratory of Wooden Material Science and Application, Beijing Forestry University, Qinghua Eastroad 35, Haidian 100083, Beijing (China)

@ Erni Ma (maerni@bjfu.edu.cn)

Received: Oct 27, 2020 - Accepted: Apr 19, 2021

Citation: Zhang R, Ma E (2021). Improving dimensional stability of Populus cathayana wood by suberin monomers with heat treatment. iForest 14: 313-319. - doi: 10.3832/ifor3684-014 [online 2021-07-01]

Communicated by: Giacomo Goli

This paper presents a wood modification method using renewable and nontoxic suberin monomers (SMs) under heat treatment to improve dimensional stability of wood from fast-growing species. Specimens of poplar (Populus cathayana) wood were impregnated with SMs and then subjected to heat treatment at $180^{\circ} \mathrm{C}$ for two hours. The untreated wood (Control), suberin monomers impregnated wood (Sub) and suberin monomers impregnated wood with heat treatment $\left(\right.$ Sub $180^{\circ} \mathrm{C}$ ) were analyzed by scanning electron microscopy (SEM), confocal laser scanning microscopy (CLSM), and Fourier transform infrared spectroscopy (FTIR). The hygroscopicity and dimensional stability of modified wood were evaluated. The results showed that SMs in the treated wood were located in the cell lumen of fibers and vessels, as well as in the cell wall which was bulked. The dimensional stability of SMs modified wood was improved, and this enhancement became more pronounced by a combination with heat treatment. The anti-swelling efficiency of Sub and Sub $180^{\circ} \mathrm{C}$ treatments were $30.0 \%$ and $49.6 \%$, respectively. The presented results showed potential of SMs treatment to develop an effective modification approach and improve dimensional stability of wood of fast-growing species, as well as to promote the reuse of suberin from the bark.

Keywords: Poplar, Wood Modification, Suberin, Dimensional Stability, Heat Treatment

other defects occur in practice frequently. The dimensional instability of wood will adversely affect its performances, especially when wood is used in furniture (Cetera et al. 2019). Wooden material can be modified by various reagents, which improved its performances in service (Yang et al. 2019, Sandberg et al. 2017, Ramezanpour et al. 2015). Polyethylene glycol (PEG) is a wood modifier commonly used to improve the dimensional stability of wood by bulking the cell wall. However, its raw materials come from petroleum, failing to cater the requirements of sustainable development. Further, toxic reagents, such as phenolic resin, urea-formaldehyde resins, are not desirable in practical application, although they provide excellent modification effects. Health is the basic requirement of family life, and the release of formaldehyde from wooden materials is an endangering factor for people's health (Yang et al. 2001). The International Agency for Research on Cancer announced in 2004 that formaldehyde is a recognized human carcinogen, which can cause human nasopharyngeal carcinoma (Cogliano et al. 2005). Formaldehyde can irritate eyes, mucous membranes and skin at certain concentrations (Euring et al. 2016), and the maximum allowable air concentration of formaldehyde indoor is 0.08 $\mathrm{mg} \mathrm{m}^{-3}$ in China (GB/T-16127 1995).

Today, many chemicals from forest and agriculture feedstocks are potentially available in large amounts (Gandini 2008). Among them, suberin is a natural aromatic- aliphatic crosslinked polyester, playing the role of protective barrier between plants and environment (Bernards 2002). Suberin prevents water loss during transport and protects plants from invasion by pathogens (Franke \& Schreiber 2007). Suberin is ubiquitous throughout the plant, particularly abundant in the cork oak (Quercus suber L.), where almost half of the total bark weight is made up of suberin (Olivella et al. 2013, Oliveira et al. 2017). In 2017, the cork production was 201,000 tons worldwide, and Portugal accounted for $55 \%$ (Aroso et al. 2017). It has been reported that $40 \%$ of cork productions were wine stoppers, and $66 \%$ of used wine stoppers went to landfill (McCallum et al. 2018). On the other hand, the cork stopper industry in Portugal and the birch pulp mills in Nordic countries generate considerable amounts of suberin-rich residues, around 40,000 tons per year (Sousa et al. 2008). Specifically, a single pulp mill processing could produce approximate 28,000 tons per year of suberin-rich residues (Krasutsky 2006). Compared with phenolic resin or other urea resins, suberin does not release toxic substances which are harmful to humans and the environment during its use. Suberin is a natural polymer which have a wide range of sources, as it can be extracted from waste bark, cork processing residue, etc. A reasonable reuse of cork residues can reduce the waste of resources and realize their high-value utilization. Therefore, the exploitation of these indus- 
trial by-products to modify fast-growing wood has vital practical significance for the reuse of bioresources and recycle of modified timber.

Suberin monomers (SMs) can be isolated from cork by depolymerizing suberin using alkaline hydrolysis (Graça 2015, Gandini et al. 2006, Oliveira et al. 2017). The main components of SMs are long-chain aliphatic acids, which is about $80-90 \%$ in mass of al the monomers obtained (Graça \& Santos 2007). The typical representatives in long chain aliphatic acids are $\omega$-hydroxyacids and $\alpha, \omega$-diacids, with chain length from $C_{16}$ to $C_{26}$ (Graça 2015). In some long-chain aliphatic acids, the chain length can even reach $C_{30}$ (Santos \& Graça 2013). On the other hand, there are a few polyaromatics monomers in SMs, such as ferulic acid, tyramine, etc., which make up from $1 \%$ to $10 \%$ of all suberin depolymerized products that have been found (Borg-Olivier \& Monties 1993, Graça \& Santos 2007, Graça 2015) The long-chain aliphatic acids and polyaromatic monomers are believed to have potential for improving wood properties. Long-chain aliphatic acids can improve dimensional stability of wood for its hydrophobicity (Graça 2015), and polyaromatic monomers improve wood performance in anti-weathering due to the benzene ring in the structure (Peng et al. 2014).

In this study, SMs were extracted from the bark of cork (Quercus suber L.) to en hance the dimensional stability of wood from fast-growing poplar (Populus cathay ana), a typical species in Northern China. To improve wood dimensional stability, we used heat treatment which is expected to redistribute SMs and partly degrade hemicelluloses. The morphological alteration and chemical characteristics of treatments were analyzed by scanning electron microscopy (SEM), confocal laser scanning microscopy (CLSM), and Fourier transform infrared (FTIR) spectroscopy. The dimensional changes of the modified wood under five relative humidity and liquid water conditions were investigated, and anti-swelling efficiency (ASE) of the specimens were calculated. Further, ASE' was used to investigate the modification mechanism of SMs treated wood (Ohmae et al. 2002, Hill 2006). The results from this study could expand the application of wood from fastgrowing species, as well as prompt a highvalued reuse of suberin.

\section{Materials and methods}

\section{Materials}

Cork samples of Algerian oak (Quercus suber L.) trees were provided by Hebei Belin Cork Co, Ltd., and were used to extract SMs. Wood specimens $\left(20 \times 20 \times 20 \mathrm{~mm}^{3}\right)$ were cut from the sapwood of fast-grow ing poplar (Populus cathayana) harvested from the Greater Khingan Mountains in China. Dichloromethane, ethanol, deionized water, methanol, sodium methoxide were obtained from the market.

\section{Modification process}

\section{Preparation of modifier}

First, the extract of cork was removed according to Sen et al. (2016). The cork samples were ground and sieved to $40-60$ mesh. Extractives of samples were obtained by sequential Soxhlet extractions with dichloromethane, ethanol, and deionized water by $6 \mathrm{~h}$ with each solvent to completely remove the extract.

SMs were prepared with the extractivefree material by alkaline methanolysis ( $\mathrm{Pe}$ reira 1988, Miranda et al. 2013). Extractivefree material was refluxed with a 3\% methanolic solution of $\mathrm{NaOCH}_{3}$ in $\mathrm{CH}_{3} \mathrm{OH}$ during 3h. The sample was filtrated and washed with methanol. The residue was refluxed with $\mathrm{CH}_{3} \mathrm{OH}$ for $15 \mathrm{~min}$ and filtrated again. The combined filtrates were acidified to $\mathrm{pH}$ 6 with $2 \mathrm{M} \mathrm{H}_{2} \mathrm{SO}_{4}$ and evaporated to dryness. The solid was dissolved in deionized water, and a modifier with a mass fraction of $8 \%$ was obtained.

\section{Specimens treatment}

Wood specimens were impregnated with SMs solution using a vacuum-pressure process. Firstly, the specimens were ovendried at $103{ }^{\circ} \mathrm{C}$, and their weights were recorded. They were then subjected to vacuum of -0.1 MPa for $30 \mathrm{~min}$ and immersed in SMs at $0.5 \mathrm{MPa}$ for $1 \mathrm{~h}$. After impregnation, the excess liquid on the surface of wood was wiped with tissue paper. Then the specimens were oven-dried at $103{ }^{\circ} \mathrm{C}$ (labelled as "Sub"). Finally, the Sub specimens were treated at $180{ }^{\circ} \mathrm{C}$ for $2 \mathrm{~h}$ (labelled as "Sub $180{ }^{\circ} \mathrm{C}$ "). The weight percent gain (WPG) and bulking coefficient (BC) for the impregnation treatment and mass loss $(\mathrm{ML})$ for the heat treatment were evaluated according to the following equations (eqn. 1 to 3 ):

$$
\begin{aligned}
& \operatorname{WPG}(\%)=\left(m_{1}-m_{0}\right) / m_{0} \cdot 100 \\
& B C(\%)=\left(v_{1}-v_{0}\right) / v_{0} \cdot 100 \\
& M L(\%)=\left(m_{1}-m_{2}\right) / m_{1} \cdot 100
\end{aligned}
$$

where $m_{0}$ and $m_{1}$ are the oven-dried weights of each wood specimen before and after impregnation (g); $m_{2}$ is the ovendried weights of each wood specimen after heat treatment $(\mathrm{g}) ; v_{0}$ and $v_{1}$ are the ovendried volumes of each wood specimen before and after impregnation $\left(\mathrm{mm}^{3}\right)$.

\section{Scanning electron microscope analysis}

The microstructure of specimens was observed by scanning electron microscope (JSM-6700F ${ }^{\circledast}$, Jeol Ltd., Tokyo, Japan). The transverse sections of the specimens were sputter-coated with gold and observed by SEM with a voltage of $15 \mathrm{KV}$.

\section{Confocal laser scanning microscopy analysis}

Suberin and lignin are naturally fluorescent substances in plant cells for its pheno- lic structure (Hutzler et al. 1998, Kitin et al. 2020). The microscopic distribution of SMs in specimens was detected by a Leica TCS SP8 confocal microscope (Leica Microsystems Inc., Wetzlar, Germany) with a krypton/argon laser emitting at wavelengths of $488 \mathrm{~nm}$. The transverse sections of the specimens with a thickness of 10-20 $\mu \mathrm{m}$ was obtained using a microtome, and the gain setting was 115 . The fluorescence intensity on the cell cavity and cell wall was measured and compared to the difference before and after treatment with the average value of 5 points.

\section{Fourier transform infrared analysis}

Some $200 \mathrm{mg}$ of $\mathrm{KBr}$ powder and 1-2 mg were taken and ground in an agate mortar. The sample was pressed using a tablet press and put into the cuvette for testing. The change of functional groups in the specimens after treatment was tested by Fourier transform infrared spectroscopy (Spectrum Two ${ }^{\mathrm{TM}}$, Perkin-Elmer Inc., Waltham, MS, USA) with a resolution of $4 \mathrm{~cm}^{-1}$ and 32 scans per specimen in the $400-4000$ $\mathrm{cm}^{-1}$ interval.

\section{Hygroscopicity and dimensional stability}

Oven-dried specimens were separately exposed to 5 different relative humidities (RHs) of $16 \%, 36 \%, 60 \%$ and $83 \%$. The $5 \mathrm{RH}$ conditions were developed by saturated salt solutions of $\mathrm{LiCl}, \mathrm{MgCl}, \mathrm{NaBr}, \mathrm{KBr}$, and $\mathrm{KNO}_{3}$ at $25^{\circ} \mathrm{C}$ (Greenspan 1977). Each treatment collectives have 4 wood replicates for all the RHs. Six additional oven-dried specimens were placed in deionized water at approximately $25^{\circ} \mathrm{C}$ for liquid water uptake in each group. Weights and dimensions along and across the grain during the process were measured at specific time intervals, by analytical balance (0.0001 g) and vernier caliper $(0.02 \mathrm{~mm})$ at the same positions marked in the specimens, respectively.

Moisture content (MC), tangential swelling rate (TSR), and volumetric swelling rate (VSR) of the specimens were calculated as follows (eqn. 4 to 8 ):

$$
\begin{aligned}
& \operatorname{MC}(\%)=\left(M_{i}-M_{0}\right) / M_{0} \cdot 100 \\
& \operatorname{TSR}_{a d}(\%)=\left(L_{a b}-L_{0}\right) / L_{0} \cdot 100 \\
& \operatorname{TSR}_{a b}(\%)=\left(L_{a d}-L_{0}\right) / L_{0} \cdot 100 \\
& \operatorname{VSR}_{a d}(\%)=\left(V_{a b}-V_{0}\right) / V_{0} \cdot 100 \\
& \operatorname{VSR}_{a b}(\%)=\left(V_{a d}-V_{0}\right) / V_{0} \cdot 100
\end{aligned}
$$

where the subscript ad represents the water vapor uptake process, $a b$ refers to the liquid water uptake process; $M_{0}$ and $M_{\mathrm{i}}$ are the weights of oven-dried treated specimens and specimens after $n$ hours of water vapor uptake (g), respectively; $L_{0}, L_{a d}$, and $L_{a b}$ are the tangential dimensions of ovendried treated specimens and specimens after $n$ hours of water vapor uptake and liq- 
uid water uptake $(\mathrm{mm})$, respectively; $V_{0}$, $V_{a d}$, and $V_{a b}$ are volumes of oven-dried treated samples and specimens after $n$ hours of water vapor uptake and $n$ hours water immersion $\left(\mathrm{mm}^{3}\right)$.

Anti-swelling efficiency (ASE) of the specimens was calculated according to eqn. 9. To further investigate the modification mechanism at the cellular level, ASE' was evaluated using eqn. 10 (Ohmae et al. 2002, Hill 2006):

$$
\begin{aligned}
& A S E(\%)=\left(V S R_{u}-V S R_{s}\right) / V S R_{u} \cdot 100 \\
& \operatorname{ASE}^{\prime}(\%)=\left(V S R_{u}-V S R_{s^{\prime}}\right) / V S R_{u} \cdot 100
\end{aligned}
$$

where $V S R_{u}$ and $V S R_{s}$ are the volumetric swelling rates of untreated wood and treated wood based on the oven-dried dimension after treatment, while $V S R_{s^{\prime}}$ is the volumetric swelling coefficient of treated wood calculated by using the oven-dried dimension before treatment.

According to Hill (2006), there are two mechanisms in the improvement of wood dimensional stability. When reagent is not cross-linked with wood cell wall, the achievement of dimensional stability is attributed to cell wall swelling (bulking) caused by the reagent; otherwise it could be due to the restrained movement of cell wall polymer. The dimensional stability calculated by ASE cannot differentiate the effect of bulking from crosslinking, whereas ASE' could eliminate the influence of reagent filling by changing the calculation method for volumetric swelling rate of the treated wood. In the calculation of ASE', the oven-dried dimension before treatment is used in the $\mathrm{VSR}_{s^{\prime}}$, then the effect of swell by reagent filling is removed. Therefore, it can further determine whether the cross-linking reaction has occurred from the results of ASE'.

The effects of modifiers on wood cell wall could have 3 cases: (i) when the improved dimensional stability of the modified wood is caused by a bulking phenomenon, then ASE' will be zero (Fig. S1 in Supplementary material); (ii) when the cross-linking occurs, then the liquid water uptake volume of the modified wood will be lower than bulking only, so ASE' takes a positive value; (iii) if the modification results in cell wall degradation, which leads to an increase in volume, then a negative value of $\mathrm{ASE}^{\prime}$ will be obtained (Ohmae et al. 2002, Hill 2006).

\section{Results and discussion}

General description of treated wood

As shown in Tab. 1, the WPG and BC of wood specimens subjected to the SMs treatment were $14.27 \%$ and $3.32 \%$, respectively. A part of SMs was introduced into the wood cell and it bulked after vacuum/ pressurize treatment. The WPG and BC of Sub $180{ }^{\circ} \mathrm{C}$ were $10.14 \%$ and $1.89 \%$, respectively, and the average mass loss for specimens of this treatment was $2.28 \%$, due to the degradation of hemicellulose and vol-
Tab. 1 - Mean ( \pm standard deviation) weight percent gain, bulking coefficient, and mass loss of the treated specimens (based on 21 replicates).

\begin{tabular}{lccc}
\hline Treatment & $\begin{array}{c}\text { Weight percent } \\
\text { gain (\%) }\end{array}$ & $\begin{array}{c}\text { Bulking } \\
\text { (\%) }\end{array}$ & $\begin{array}{c}\text { Mass loss } \\
\text { (\%) }\end{array}$ \\
\hline Sub & $14.27 \pm 0.01$ & $3.32 \pm 0.01$ & - \\
\hline Sub $180^{\circ} \mathrm{C}$ & $10.14 \pm 0.03$ & $1.89 \pm 0.01$ & $2.28 \pm 0.00$ \\
\hline
\end{tabular}

atilization of low molecular mass monomers in SMs.

\section{Microstructure of the specimens}

Fig. 1 shows the SEM images of honeycomb cell structure in the cross-sections of specimens. SMs entered the wood cells by

vacuum/pressurize treatment at room temperature, and deposited as particles (Fig. 1e-h). Compared with the Control, a part of the cell lumen of wood vessels and fibers were totally or partially filled with SMs after impregnation (Fig. 1e, Fig. 1f), which
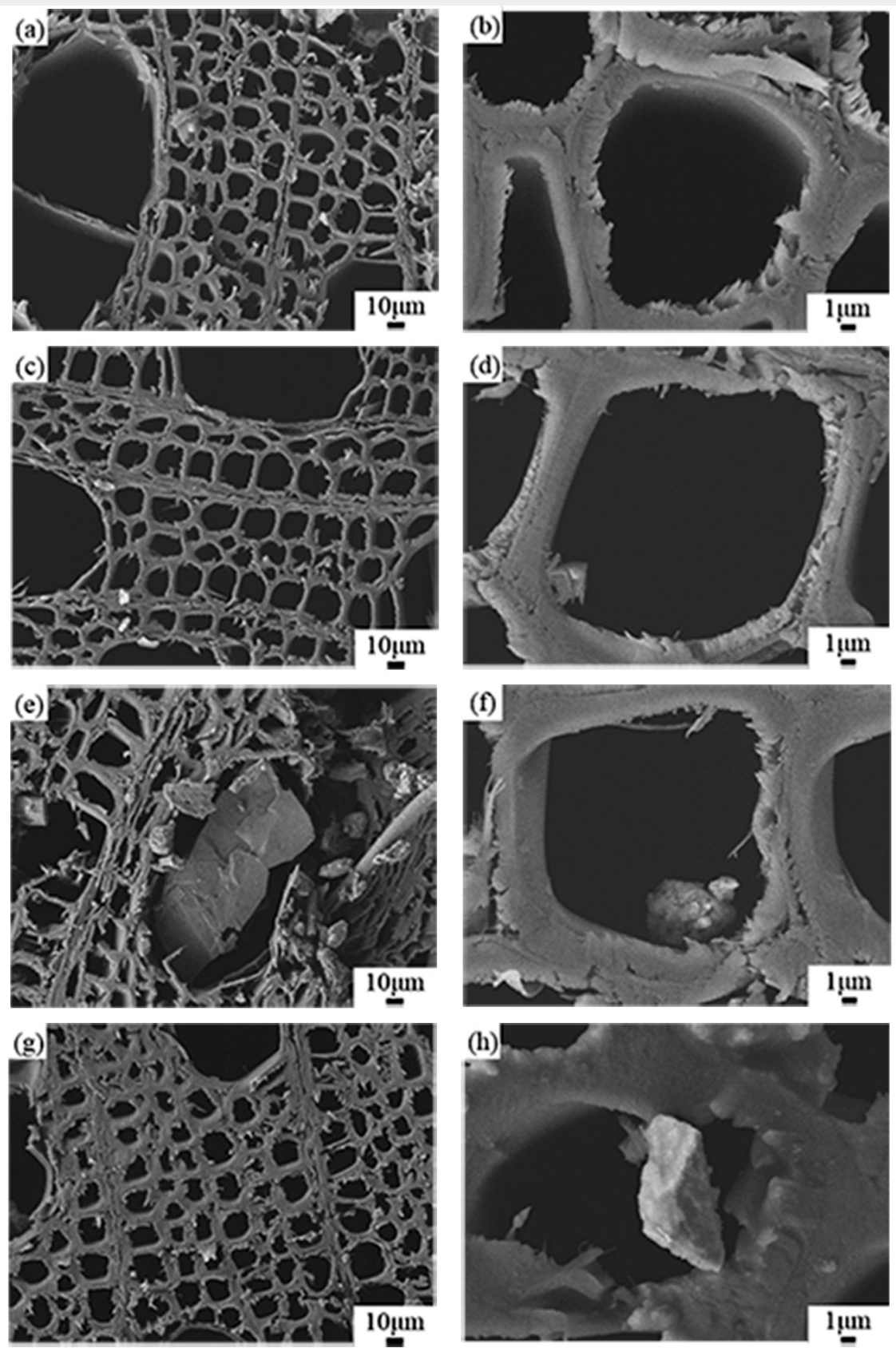

Fig. 1 - SEM images of wood cross-sections for the Control (a, b), Control $180{ }^{\circ} \mathrm{C}(c, d)$, Sub $(e, f)$ and Sub $180^{\circ} \mathrm{C}(g, h)$ specimens. Magnification of $500 \times$ for (a), (c), (e) and (g), and $4000 \times$ for (b), (d), (f) and (h). 


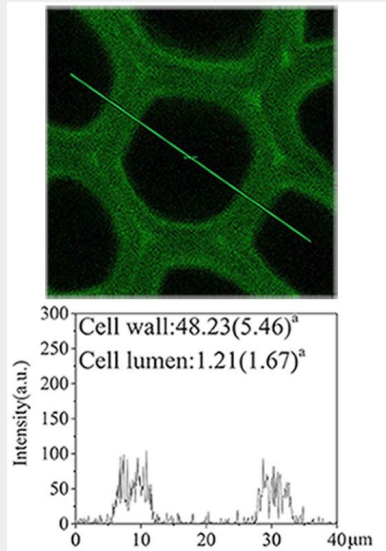

(a) Control

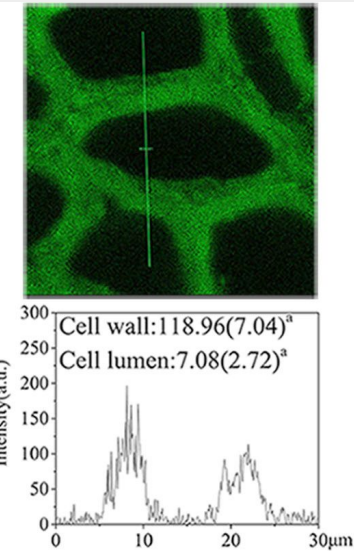

(b) Sub

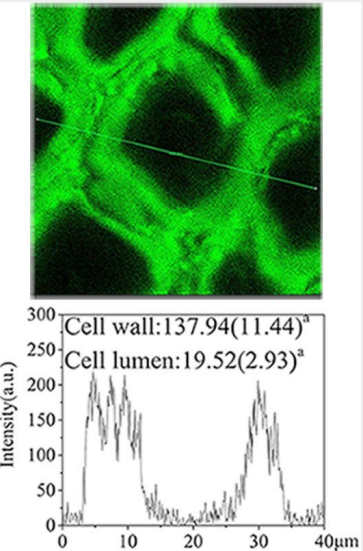

(c) Sub $180^{\circ} \mathrm{C}$

Fig. 2 - CLSM images showing the cross-sections of wood specimens for Control, Sub, and Sub $180^{\circ} \mathrm{C}$ treatments and the corresponding intensity of fluorescence signal. (a): Average values (standard deviation in parenthesis) from five replicates.

SMs in granular or membranous form created a barrier reducing the contact between wood and water. After heat treatment at $180^{\circ} \mathrm{C}$, the cell structure remained intact, implying the heat treatment temperature and time were moderate. Comparing Fig. 1C with Fig. 1g, the cell wall of Sub $180^{\circ} \mathrm{C}$ was significantly thicker than that of Control $180^{\circ} \mathrm{C}$, due to the uniform attachment of SMs to the inner cell wall after heat treatment. The SMs particles in Fig. $1 \mathrm{~h}$ was smoother than Fig. 1f, which proved that the SMs particles had fluidity with heat treatment again (Sousa et al. 2008).
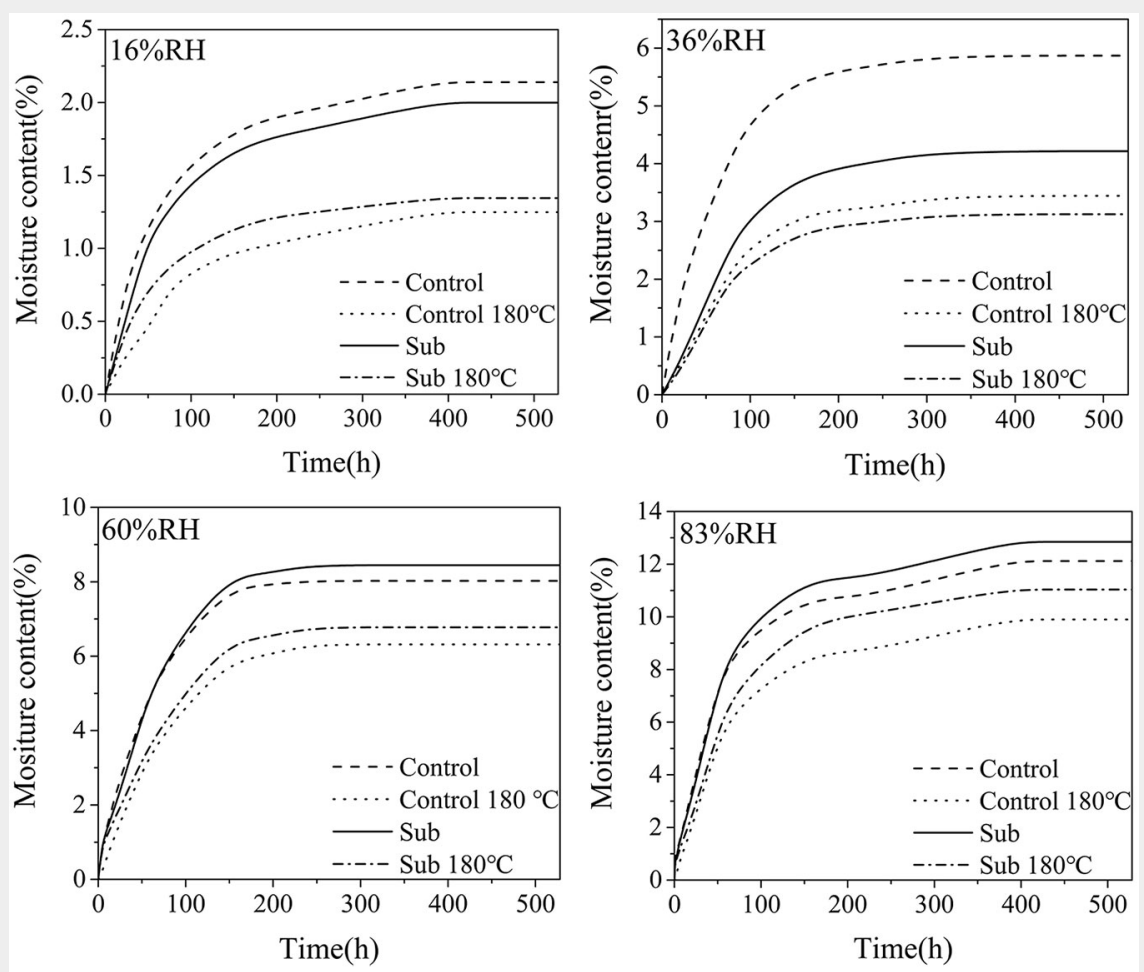

Fig. 3 - Moisture water uptake processes under different RH conditions (at $25^{\circ} \mathrm{C}$ ) for the wood specimens subjected to different treatment.

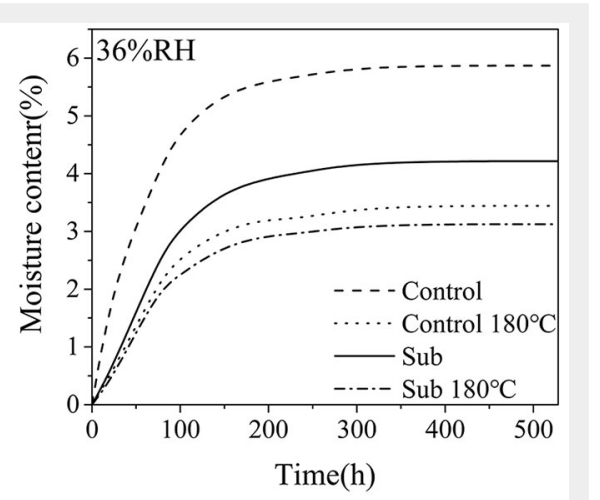

\section{SMs distribution in the specimens}

Fig. 2 illustrates the CLSM images of wood specimens from Control, Sub, and Sub $180^{\circ} \mathrm{C}$ treatments. The aromatic compounds have a fluorescent effect under CLSM, and brighter areas represent higher aromatic concentration (Kutscha \& Mcormond 1972). In Fig. 2a, the green light fluorescence in the compound middle lamella was brighter than cell wall, suggesting the presence of more lignin in the compound middle lamella. Fig. 2 also shows the average fluorescence intensity estimated by five random points from the cell wall or cell lumen. In the Control, the average intensity

Fig. 3 presents the water vapor uptake processes at four $\mathrm{RH}$ conditions for the specimens. In low RH ( $16 \%$ and $36 \% \mathrm{RH})$, the moisture content of Sub was lower than Control. However, under high RH (60\% and $83 \% \mathrm{RH}$ ), this relation was reversed.

The results of water vapor uptake for the SMs treated wood are similar to those of PEG modified wood. Bjurhager et al. (2010) investigated the equilibrium moisture content (EMC) of PEG 600 modified oak wood under different $\mathrm{RH}$, finding that it was lower than expected when $\mathrm{RH}$ was below $55 \%$, while it was the opposite when $\mathrm{RH}$ was above $55 \%$. The findings of Meints et al. (2018) showed similar EMC results for PEG 400/PEG 1000 modified oak wood under high $\mathrm{RH}$.

Both SMs and PEG have a large number of hydroxyl groups. As suggested by Bjur- 
hager et al. (2010), hydrogen bonding takes place between PEG and hydroxyl groups in the cell wall of PEG modified wood. Under different RH, the "PEGwood" interface reacted differently to moisture. The mechanism could be deduced from PEG modified wood for their similar functional groups. When the $\mathrm{RH}$ was low, the water molecules cannot cut down the hydrogen bonds between the SMs and wood (Fig. 4b). In addition, SMs filled the cell wall pores, thereby reducing the contact of moisture with wood substance (Han et al. 2020), and the hydrophobic long-chain aliphatic acids prevented water from entering the vessels (Graça 2015); thus the SMs treated wood had a lower moisture content. Whereas under high $\mathrm{RH}$ conditions, the hydrogen bonds between the SMs and wood were broken (Fig. 4C), as water molecules bonded with the SMs and the hydroxyl groups in the wood cell wall; therefore, the moisture content of Sub treated wood was higher than the Control.

The moisture content of the Control 180 ${ }^{\circ} \mathrm{C}$ specimens was reduced during the water vapor uptake process due to the degradation of hemicellulose (Fig. 3). At the same time, the moisture content of Sub $180{ }^{\circ} \mathrm{C}$ wood was also reduced. Compared with Control, the moisture content of Sub $180{ }^{\circ} \mathrm{C}$ specimens was reduced by $35.6 \%$, $46.76 \%, 15.56 \%$, and $5.74 \%$ under $\mathrm{RH}$ of $16 \%$, $36 \%, 60 \%, 83 \%$ at $528 \mathrm{~h}$, respectively. Regarding the moisture content, the relationship between Sub $180^{\circ} \mathrm{C}$ and Control $180^{\circ} \mathrm{C}$ treatments was similar to that between Sub and Control treatments. The moisture content of impregnated specimens was lower than that of unimpregnated ones at $36 \% \mathrm{RH}$, and the phenomenon was the opposite at high $\mathrm{RH}$. This indicates that the "SMs-wood" interface existed in Sub $180^{\circ} \mathrm{C}$ wood, thus the hydroxyl groups in SMs were still present after heat treatment. The moisture content of Control $180{ }^{\circ} \mathrm{C}$ specimens was lower than that of Sub $180{ }^{\circ} \mathrm{C}$ specimens under $\mathrm{RH}$ of $60 \%$, but this relation was reversed for the Control and Sub specimens. This support the hypothesis that the interface of "SMs-wood" in Sub $180{ }^{\circ} \mathrm{C}$ samples was weaker than that of

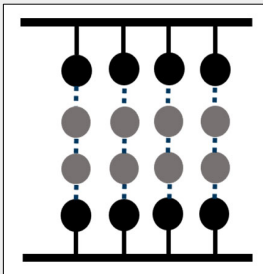

(a) Hydrogen bonding

Hydroxyl of wood

Hydroxyl of water molecule

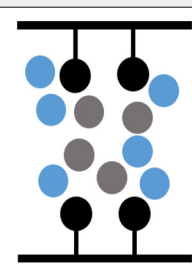

(c) High RH
Fig. 4 - Schematic diagram of the interaction among SMs, wood, and water. (a): Hydrogen bonding between SMs and wood; (b): interactions among water molecules, SMs, and wood in low RH; (c): interactions among water molecules, SMs, and wood in high $\mathrm{RH}$.
Sub samples, due to the degradation of hemicellulose after heat treatment.

\section{Dimensional stability of the specimens}

Fig. S3 (Supplementary material) presents the tangential and volumetric swelling rate of specimens under different RHs. After heat treatment, the tangential and volumetric swelling rate of Control $180^{\circ} \mathrm{C}$ wood was significantly lower than Control wood, and the tangential and volumetric swelling rate of Sub $180{ }^{\circ} \mathrm{C}$ was lower than the Control. Specifically, the tangential swelling rate was reduced by $13.18 \%$ to $24.63 \%$ at $528 \mathrm{~h}$, and the volumetric swelling rate was reduced by $12.24 \%$ to $34.00 \%$ at $528 \mathrm{~h}$. With the heat treatment, the SMs were more evenly distributed in the wood cells (Fig. 1), and this reduced the contact between water and wood. Compared with the Control $180^{\circ} \mathrm{C}$ samples, the Sub $180^{\circ} \mathrm{C}$ sample wood had a lower volumetric swelling rate at $16 \% \mathrm{RH}, 36 \% \mathrm{RH}$, and $60 \% \mathrm{RH}$. However, under $83 \% \mathrm{RH}$, the volumetric swelling rate of Sub $180^{\circ} \mathrm{C}$ specimens was similar to the of Control $180^{\circ} \mathrm{C}$ specimens. Cui et al. (2017) studied the dimensional changes of $\mathrm{ZnO}$ composite heat treatment wood under $65 \% \mathrm{RH}$, finding that it had $1.6 \%$ tangential and $2.2 \%$ volumetric swelling. In this study, the swelling rate of Sub $180{ }^{\circ} \mathrm{C}$ wood under $60 \% \mathrm{RH}$ was lower than the aforementioned $\mathrm{ZnO}$ composite heat treatment modified wood. Therefore, SMs compound after heat treatment can better prevent wood from absorbing water vapor.

Fig. 5 presents the tangential and volumetric swelling rate of specimens through liquid water uptake. The swelling rate of Sub samples was reduced by $29.98 \%$ compared to Control samples, because SMs filled in cell lumen and cell wall. Concerning the Sub $180{ }^{\circ} \mathrm{C}$ treatment, the dimensional stability was further enhanced compared with Control, as the tangential and volumetric swelling rate of Sub $180{ }^{\circ} \mathrm{C}$ specimens was reduced by $21.37 \%$ and $32.85 \%$ at $192 \mathrm{~h}$. Bulking of cell wall by SMs, better distribution of SMs within wood cell wall, and the degradation of hemicellulose after heat treatment, are supposed to be the reasons accounting for the most favorable dimensional stability of the Sub $180{ }^{\circ} \mathrm{C}$ treated wood. Baar et al. (2021) reported a

Tab. 2 - ASE and ASE' of specimens in 192h during liquid water uptake from 6 replicates.

\begin{tabular}{cccc}
\hline \multirow{2}{*}{ Parameter } & \multicolumn{3}{c}{ Treatment } \\
\cline { 2 - 4 } & Control $180^{\circ} \mathrm{C}$ & Sub & Sub $180^{\circ} \mathrm{C}$ \\
\hline ASE (\%) & $18.1 \pm 6.61$ & $30.0 \pm 4.28$ & $49.6 \pm 4.12$ \\
\hline ASE' (\%) & $0.2 \pm 0.06$ & $-0.0 \pm 0.07$ & $0.2 \pm 0.07$ \\
\hline
\end{tabular}

Fig. 5 - Tangential (a) and volumetric (b) swelling rate of the specimens through liquid water uptake.

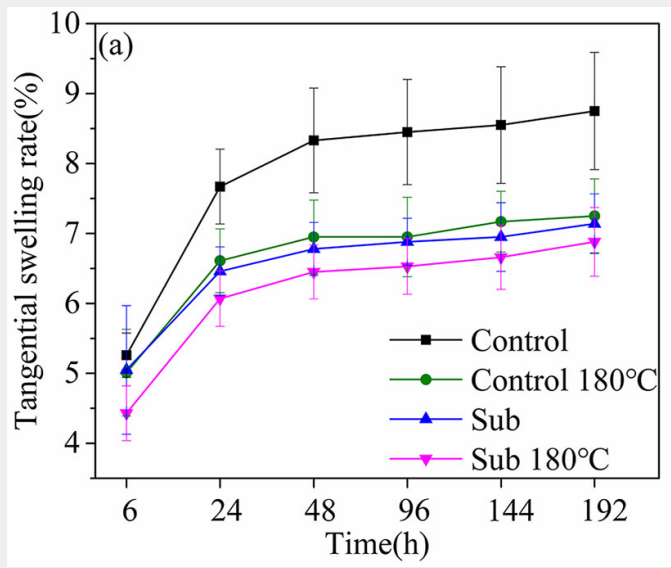


hemp oil composite heat-treated wood, which tangential and volumetric swelling rate were about $8.5 \%$ and $15.0 \%$ through liquid water uptake. In this study, Sub $180^{\circ} \mathrm{C}$ wood had a lower tangential and volumetric swelling rate, which were $6.9 \%$ and $8.9 \%$, respectively.

Tab. 2 lists the ASE and ASE' of the specimens subject to different treatments. At WPG of $13.2 \%$, the ASE of the Sub specimens was $30.0 \%$, and that of the Sub $180{ }^{\circ} \mathrm{C}$ specimens was $49.6 \%$, which once again indicate higher dimensional stability. The ASE' of glutaraldehyde modified wood was $18 \%$ with 14\% WPG (Xiao et al. 2010). Compared with glutaraldehyde modified wood, that of Control $180^{\circ} \mathrm{C}$, Sub and Sub $180^{\circ} \mathrm{C}$ modified wood could be considered as 0 , suggesting the SMs just impregnated the cell wall and coated the inner surface of cell lumen without cross-linking with the cell wall substance in the Sub and Sub 180 ${ }^{\circ} \mathrm{C}$ wood (Fig. 2). Thermosetting resin modified wood was reported by many researchers (Deka \& Sailkia 2000, Ohmae et al. 2002). An average ASE value of $45.6 \%$ was achieved for phenol formaldehyde (PF) modified wood with $13.8 \%$ WPG (Ohmae et al. 2002). This study proved that SMs and PF have similar effects on wood ASE. However, PF modified wood have a different mechanism underlying the dimensional stability in respect to Sub $180{ }^{\circ} \mathrm{C}$ modified wood (0.2\% ASE' for Sub $180{ }^{\circ} \mathrm{C}$, 21.5\% ASE' for PE modified wood).

\section{Conclusions}

To improve the dimensional stability of wood from fast-growing species, an effective and sustainable modification approach was reported here. Poplar specimens were impregnated with SMs and then subjected to heat treatment. Compared with Control, the volumetric swelling rate of Sub and Sub $180^{\circ} \mathrm{C}$ modified wood was significantly reduced. SMs filled in cell lumen, which not only blocked the vessels within wood but also reduced the contact between wood and water. In addition, SMs could enter into the wood cell wall and bulked it, so as to reduce its swelling. After heat treatment, the distribution of SMs became much more uniform and part of hemicelluloses was degraded. The dimensional stability of modified wood was further enhanced by the heat treatment.

The SMs modified wood has excellent performances and is a fully green product, which can be used as an ecologically friendly material. Future research will focus on methods based on acids and biological enzymes aimed to polymerize SMs in the wood and reduce the water vapor uptake of SMs modified wood under high relative humidity. Besides, long-chain aliphatic acids and polyaromatic monomers of the SMs can be separated and wood can be modified with long-chain aliphatic acids or polyaromatic monomers, aiming at different purposes, to further realize an efficient and reasonable utilization of SMs.

\section{Acknowledgments}

This work was supported by the Fundamental Research Funds for the Central Universities of China (No. 2015ZCQ-CL-01). The authors would also like to thank Xingang Zhao, general manager of Heibei Belin Cork Co., Ltd., for providing cork samples.

\section{References}

Aroso IM, Araújo AR, Pires RA, Reis RL (2017). Cork: current technological developments and future perspectives for this natural, renewable and sustainable material. ACS Sustainable Chemistry and Engineering 5 (12): 11130-11146. doi: 10.1021/acssuschemeng.7bo0751

Baar J, Brabec M, Slávik R, Cermak P (2021). Effect of hemp oil impregnation and thermal modification on European beech wood properties. European Journal of Wood and Wood Products 79: 161-175. - doi: 10.1007/s00107-02001615-9

Bernards MA (2002). Demystifying suberin. Canadian Journal of Botany 80: 227-240. - doi: 10.113 9/b02-017

Bjurhager I, Ljungdahl J, Wallstr ML, Gamstedt K, Berglund $L$ (2010). Towards improved understanding of PEG impregnated waterlogged archaeological wood: a model study on recent oak. Holzforschung 64 (2): 243-250. - doi: 10.151 5/hf.2010.024

Borg-Olivier O, Monties B (1993). Lignin, suberin, phenolic-acids and tyramine in the suberized, wound-induced potato periderm. Phytochemistry 32 (3): 601-606. - doi: 10.1016/S0031-9422 (00) $95143-4$

Cetera P, Russo D, Milella L, Todaro L (2019). Thermo-treatment affects Quercus cerris L. wood properties and the antioxidant activity and chemical composition of its by-product extracts. Industrial Crops and Products 130: 380388. - doi: 10.1016/j.indcrop.2018.12.099

Cogliano VJ, Grosse Y, Baan RA, Straif K, Secre$\tan M B$, Ghissassi FE (2005). Meeting Report: Summary of IARC Monographs on formaldehyde, 2-Butoxyethanol, and 1-tert-Butoxy-2Propanol. Environmental Health Perspectives 113 (9): 1205-1208. - doi: 10.1289/ehp.7542

Cordeiro N, Belgacem MN, Silvestre AJD, Neto CP, Gandini A (1998). Cork suberin as a new source of chemicals. 1. Isolation and chemical characterization of its composition. International Journal of Biological Macromolecules 22 (2): 71-80. - doi: 10.1016/S0141-8130(97)00090-1 Cui W, Zhang N, Xu M, Cai L (2017). Combined effects of $\mathrm{ZnO}$ particle deposition and heat treatment on dimensional stability and mechanical properties of poplar wood. Scientific Reports 7 (1): 9961. - doi: 10.1038/s41598-01710606-5

Deka M, Sailkia CN (2000). Chemical modification of wood with thermosetting resin: effect on dimensional stability resin: effect on dimensional stability and strength property. Bioresource Technology 73 (2): 179-181. - doi: 10.1016/ Sog60-8524(99)00167-4

Euring M, Kirsch A, Schneider P, Kharazipour A (2016). Lignin-laccase-mediator-systems (LLMS) for the production of binderless medium density fiberboards (MDF). Journal of Materials Science Research 5 (2): 7. - doi: 10.5539/jmsr.v5n $2 \mathrm{p} 7$
Franke R, Schreiber L (2007). Suberin - a biopolyester forming apoplastic plant interfaces. Current Opinion in Plant Biology 10 (3): 252-259. - doi: 10.1016/j.pbi.2007.04.004

Gandini A (2008). Polymers from renewable resources: a challenge for the future of macromolecular materials. Macromolecules 41: 94919504. - doi: 10.1021/ma801735u

Gandini A, Neto CP, Silvestre AJD (2006). Suberin: a promising renewable resource for novel macromolecular materials. Progress in Polymer Science 31 (10): 878-892. - doi: 10.1016/j.prog polymsci.2006.07.004

GB/T-16127 (1995). Hygienic standard for formaldehyde in indoor air of house. Standardization Administration of the PRC, Beijing, China, pp. 1.

Graça J (2015). Suberin: the biopolyester at the frontier of plants. Frontiers in Chemistry 3 (4): 62. - doi: $10.3389 /$ fchem.2015.00062

Graça J, Santos S (2007). Suberin: a biopolyester of plants' skin. Macromolecular Bioscience 7: 128-135. - doi: 10.1002/mabi.200600218

Greenspan L (1977). Humidity fixed-points of binary saturated aqueous-solutions. Journal of Research of the National Bureau of Standards A Physics and Chemistry 81: 89-96. - doi: 10.602 8/jres.081A.011

Han X, Wang Z, Zhang Q, Pu J (2020). An effective technique for constructing wood composite with superior dimensional stability. Holzforschung 74 (5): 435-443. - doi: 10.1515/hf-20190176

Heinämäki J, Pirttimaa MM, Alakurtti S, Pitkänen HP, Kanerva H, Hulkko J, Paaver U, Aruväli J, Yliruusi J, Kogermann K (2017). Suberin fatty acids from outer birch bark: isolation and physical material characterization. Journal of Natural Products 80: 916-924. - doi: 10.1021/acs.jnat prod.6boo771

Hill CAS (2006). Wood modification: chemical, thermal and other processes. John Wiley and Sons Ltd, Chichester, UK, pp. 239.

Huang Y, Li G, Chu F (2018). In situ polymerization of 2-hydroxyethyl methacrylate (HEMA) and 3-(methacryloxy) propyltrimethoxysilane (MAPTES) in poplar cell wall to enhance its dimensional stability. Holzforschung 73 (5): 1-6. doi: 10.1515/hf-2018-0139

Hutzler P, Fischbach R, Heller W, Jungblut TP, Reuber S, Schmitz R, Veit M, Weissenböck G, Schnitzler J (1998). Tissue localization of phenolic compounds in plants by confocal laser microscopy. Journal of Experimental Botany 49 (323): 953-965. - doi: 10.1093/jexbot/49.323.953 Kitin P, Nakaba S, Hunt CG, Lim S, Funada R (2020). Direct fluorescence imaging of lignocellulosic and suberized cell walls in roots and stems. AoB Plants (4): 4. - doi: 10.1093/aobpla/ plaa032

Krasutsky PA (2006). Birch bark research and development. Natural Product Reports 23: 919942. - doi: 10.1039/b606816b

Kutscha NP, Mcormond RR (1972). The suitability of using fluorescence microscopy for studying lignification in balsam fir. Technical Bulletin 62, Life Sciences and Agriculture Experiment Station, Orano, ME, USA, pp. 15. [online] URL: http://digitalcommons.library.umaine.edu/cgi/vi ewcontent.cgi?article $=1135 \&$ context $=$ aes_tech bulletin 
Labbé N, Rials TG, Kelley SS, Cheng Kim ZM JY, Li Y (2005). FT-IR imaging and pyrolysis-molecular beam mass spectrometry: new tools to investigate wood tissues. Wood Science and Technology 39 (1): 61-76. - doi: 10.1007/s00226-004-027 4-0

McCallum CS, Strachan N, Bennett SC, Forsythe WG, Garrett MD, Hardacre C, Morgan K, Sheldrake GN (2018). Catalytic depolymerisation of suberin rich biomass with precious metal catalysts. Green Chemistry 20: 2702-2705. - doi: 10.10 39/C8GC00605A

Meints T, Hansmann C, Gindl-Altmutter W (2018). Suitability of different variants of polyethylene glycol impregnation for the dimensional stabilization of oak wood. Polymers 10 (1): 81. - doi: 10.3390/polym10010081

Miranda I, Gominho J, Pereira H (2013). Cellular structure and chemical composition of cork from the Chinese cork oak (Quercus variabilis). Journal of Wood Science 59 (1): 1-9. - doi: 10.100 7/s10086-012-1300-8

Ohmae K, Minato K, Norimoto M (2002). The analysis of dimensional changes due to chemical treatments and water soaking for hinoki (Chamaecyparis obtusa) wood. Holzforschung 56 (1): 98-102. - doi: 10.1515/HF.2002.016

Oliveira HD, Yoon B, Michaud V, Nam J, Suhr J (2017). All natural cork composites with suberin-based polyester and lignocellulosic residue. Industrial Crops and Products 109: 843849. - doi: 10.1016/j.indcrop.2017.09.044

Olivella MA, Fernández I, Cano L, Jove P, Oliveras A (2013). Role of chemical components of cork on sorption of aqueous polycyclic aromatic hydrocarbons. International Journal of Environmental Research 7 (1): 225-234. - doi: 10.1177/0734242X13507967

Peng Y, Liu R, Cao J, Chen Y (2014). Effects of UV weathering on surface properties of polypropylene composites reinforced with wood flour, lignin, and cellulose. Applied Surface Science 317: 385-392. - doi: 10.1016/j.apsusc.2014.08.140 Pereira H (1988). Chemical composition and variability of cork from Quercus suber L. Wood Science and Technology 22: 211-218. - doi: 10.1007/ BFo0386015

Ramezanpour M, Tarmian A, Taghiyari HR (2015). Improving impregnation properties of fir wood to acid copper chromate (ACC) with microwave pre-treatment. iForest - Biogeosciences and Forestry 8 (1): 89-94. - doi: 10.3832/ifor1119-007 Sandberg D, Kutnar A, Mantanis G (2017). Wood modification technologies - a review. iForestBiogeosciences and Forestry 10 (6): 895-908. doi: 10.3832/ifor2380-010

Santos S, Graça J (2013). Stereochemistry of C-18 monounsaturated cork suberin acids determined by spectroscopic techniques including $\mathrm{H}$ 1-NMR multiplet analysis of olefinic protons. Phytochemical Analysis 25: 192-200. - doi: 10.100 2/pca.2491

Sen A, Zhianski M, Glushkova M, Petkova K, Ferreira J, Pereira $\mathrm{H}$ (2016). Chemical composition and cellular structure of corks from Quercus suber trees planted in Bulgaria and Turkey. Wood Science and Technology 50 (6): 12611276. - doi: 10.1007/s00226-016-0836-y
Sousa AF, Gandini A, Silvestre AJ, Pascoal Neto C (2008). Synthesis and characterization of novel biopolyesters from suberin and model comonomers. Sustainable Chemistry and Pharmacy 1020-1025. - doi: 10.1002/cssc.200800178

Xiao Z, Xie Y, Militz H, Mai C (2010). Effects of modification with glutaraldehyde on t-he mechanical properties of wood. Holzforschung 64 (4): 475-482. - doi: 10.1515/hf.2010.058

Yang $X$, Zhang YP, Chen D, Chen WG, Wang $R$ (2001). Eye irritation caused by formaldehyde as an indoor air pollution - a controlled human exposure experiment. Biomedical and Environmental Sciences 14 (3): 229-236. [online] URL: http://europepmc.org/article/med/11723723 Yang T, Cao J, Ma E (2019). How does delignification influence the furfurylation of wood? Industrial Crops and Products 135: 91-98. - doi: 10.101 6/j.indcrop.2019.04.019

\section{Supplementary Material}

Fig. S1 - Relative changes in ASE and ASE' due to different forms of modification.

Fig. S2 - Fourier transform infrared (FTIR) spectra for the Control, Control $180^{\circ} \mathrm{C}$, Sub and Sub $180^{\circ} \mathrm{C}$.

Fig. S3 - Tangential and volumetric swelling rate of the specimens through moisture water uptake.

Link: Zhang_3684@supploo1.pdf 